\title{
Sociality Revisited Setting a New Agenda
}

\author{
Nicholas J. Long and Henrietta L. Moore, University of Cambridge
}

\begin{abstract}
It is time for a revitalized theory of human sociality. This theory recognizes that humans are always embedded in a dynamic matrix of relations with human, non-human, and inhuman others, but combines this recognition with attention to the distinctive capacities of human subjects. It thus builds on recent theories of actor-networks and affect, whilst going beyond their limitations.
\end{abstract}

Keywords: sociality, human subjectivity, ethical imagination, actor-network theory, affect

What would an anthropological theory of human sociality look like post-Strathern, post-affect theory, and post-ANT (Actor-Network Theory)? It would certainly need to take on board the important insights and critiques that such paradigms have offered - but should also move beyond them to address their weaknesses. It would need to be able to account for the tremendous variety of forms that can be assumed by the sociality of humans - if not other entities - a variety that appears to be ever-burgeoning as new innovations in science and technology allow human beings to extend their imaginative and practical reach. It would need to engage with the ongoing problematic of virtuality - the fact that for all of human history, human beings have shown both a capacity to fantasize about forms of sociality that don't exist and an ability to remake the forms of sociality that they already have. As such, we argue, it would need to reject the flattening impulse within a great deal of recent critical theory, which, in a self-styled attempt to 'dethrone' the figure of 'the human subject' (e.g., Clough 2008), runs the danger of reducing human sociality to nothing more than the relationality between various beings or actants, or the transfer of affective energies between undifferentiated slabs of biological matter (Clough 2010; Venn 2010). Whether or not 'the human subject' should keep its throne is, as the papers in this collection reveal, a matter for ongoing and vibrant debate. But one conclusion is clear: dethroned or not, the human subject needs to remain in the palace. For attending to the distinctiveness of humans (and that of other entities) is not only the most profitable way to make sense of the plethora of new directions in which human sociality is unfolding in anthropological fieldsites around (and beyond) the world - it also does the greatest justice to those critical theories that would urge social scientists to develop symmetrical analyses or to pay attention to the biological dimensions of being human. 


\section{What Is Sociality?}

You might well ask. The term 'sociality' has become increasingly prominent in sociocultural anthropology and the humanities over the last few decades - and it is easy to see why. The term has a lot of potential. Appealingly processual, it promises to overcome many of the drawbacks associated with the more static and bounded objects of enquiry that dominated many branches of twentieth-century social science, such as 'society', or formal patterns of 'social relations'. The emphasis on process also offers advantages over approaches that sought to study 'the social', conceiving this as a product of either 'social relations' or 'social interaction' - an approach which was doomed to founder because, logically and existentially, sociality cannot 'precede' its articulations, but is rather coextensive with, and as, articulation (Haver 1996: xiv).

Yet the full implications of what sociality actually is, and how the concept might most profitably be used, are often left obscure. Frustratingly, the term has been used in a startlingly divergent number of ways by anthropologists and others - ranging from the experience of co-presence with other humans, as in a crowded cinema (Chau 2006) to the forming of politically motivated associational communities (Sunder Rajan 2008). Its casual usage can thus seem to denote anything - or nothing. Yet this problem of definitional haziness could be looked at differently, as evidence of human sociality's capacity to take many forms. What is in order, therefore, is not a very specific, circumscribed definition of sociality, nor loose talk of a generic 'sociality' or 'capacities to "be social", but rather a theory of human sociality - which is to say any sociality involving humans - that can account for its diverse manifestations, its plasticity and fragility, and also its possible resilience.

Our preferred approach is to conceptualize human sociality as a dynamic relational matrix within which human subjects are constantly interacting in ways that are coproductive, continually plastic and malleable, and through which they come to know the world they live in and find their purpose and meaning within it. Sociality, then, is a foundational concept. This builds upon and extends the arguments championed by Marilyn Strathern and Christina Toren in the 1989 Manchester Debate in Anthropological Theory, in which Strathern suggested that sociality be understood as 'the relational matrix which constitutes the life of persons', who in turn should be apprehended as 'simultaneously containing the potential for relationships and always embedded in a matrix of relationships with others' (Strathern et al. 1990: 8-10). The importance of this, according to Toren, was that sociality drew anthropologists' attention to 'dynamic social processes in which any person is inevitably engaged, rather than a set of rules or customs or structures or even meanings that exists as a system independently of the individual who is to be socialised' (ibid.: 19).

Yet this original formulation now presents a number of conceptual ambiguities that need clarification in light of developments and challenges that have been posed within anthropological theory over the past twenty years. What, for example, is 'a person'? What 'others' can and should be included within our understanding of the relational matrix? What is the place of non-humans, objects and 'things' in a theory of sociality? How can we best incorporate into the model an understanding of those situations in which humans appear to be affected by the presence or actions of others around them, despite the fact that they have no ostensible 'relationship' with them; a process Clough 
(2010: 224) describes as 'the sociality of the transmission of force or intensity across bodies'? And how can we account for the manifold forms of human sociality?

Two contemporary perspectives on these questions emerge in the papers by Christina Toren and Henrietta Moore, both of whom underscore the analytical importance of ontogeny, intersubjectivity, human inherence in an environing world, and the developmental plasticity of human biology - including the brain. Toren's paper sets out her own distinctive vision of the anthropological project, one in which sociality is taken as foundational because intersubjectivity - which she defines as 'the capacity for recursive thought that makes human learning a micro-historical process' - means that a human is always already embedded in social relations lived within, and through, an environing world, and consequently the carrier of a unique collectivecum-personal history. Toren builds upon this argument to critique recent work that has sought to reify 'sociality' as a distinctive capacity or module of the human mind. Developing an approach informed in part by dynamic systems theory, she argues that no aspects of human development should be seen as being outside of sociality, and that anthropological attention should properly be directed to the full range of microhistorical processes by which persons are constituted over their entire lifespans. As such, she proposes a unified model of human being, in which distinctions such as those between matter and information or biology and culture are collapsed, but in which sociality stands at the core.

This raises the question of how uncritically we should engage with the category of 'the human', an issue taken up directly in Henrietta Moore's analysis of the socialities of the inorganic. Moore's approach to sociality adopts a more expansive notion of context than Toren's. While Toren argues that humans necessarily imagine and interact through an environing world, and that approaches such as actor-network theory, that would afford agency to non-human actants, are therefore unnecessary or unhelpful, Moore sees greater potential in analysing the vitalism and affectivity of matter, and its capacity to have formative influences on human lives and relations. Yet she is also adamant that this should not distract us from acknowledging the distinctiveness of human sociality. As she argues, the difficulties encountered by engineers when trying to successfully design a 'social robot' point to the significance of autopoiesis and humans' intersubjective development within a dynamic context for fostering a recognizably human sociality - which involves the use of representation and signification to coordinate knowledge, higher order cognition, and affect. Anthropology's long-standing interest in humans' linguistic and representational abilities must therefore continue, provided it is seen that these emerge out of a 'biologically cultural engagement with an environment'. Secondly, she argues that the contemporary use of avatars, another 'inorganic sociality', reveals the distinctively human capacities to project notions of 'the environment' forwards and backwards in space and time, including into parallel, virtual realms, where things of the imagination can be ascribed with attributes, qualities and attachments. These projections constitute crucial dimensions of the matrices of relations in which humans are involved - and as such, even in a world understood to be replete with different agencies and affectivities, human sociality stands out as a distinctive and vibrant concern. 


\section{Sociality, Ethics, and Imagination}

A theory of sociality therefore needs to combine attention to the dynamism of the relational matrix in which humans are embedded with a theory of the ways in which, and the extent to which, humans in any given context come to reflect upon that matrix, and might be driven to act upon it, in an attempt to open 'affective and relational virtualities' (Foucault 1997: 138). This latter enterprise was a principal concern of the later Foucault's writings on ethics - and has been taken up with political vibrancy within such fields as queer theory, in which the recognition that we are always in relations with others instigated several attempts to imagine new, emancipatory, and non-heteronormative understandings of how that relationality might be managed or acted upon (Haver 1996; Bersani 2000; Tuhkanen 2005). Such scholarship reminds us that the recognition of human sociality as a dynamic matrix of relations is not just an ontological or theoretical question, but always contains both ethical and political dimensions - not least because human dynamic matrices are shot through with inequalities of resources and capacity, and with theories and ideas about those differentials.

These aspects of sociality-as-lived both mould the discursive and material environments with which human beings engage from birth, and indicate that one's own sociality, and the impulses that underpin it, might be at least partly amenable to control. This could be via processes of conscious reflection and thought, but it might also involve affective, fantasmic and highly embodied engagements with forms of unknowing and incomprehensibility, as Moore (2011: 17-18) highlights in her notion of the ethical imagination. Theorizing human sociality requires a sophisticated account of agency, motivation, intentionality and desire: in short, an understanding of the human subject as he or she exists in a given place and time. This is not because we wish to reinstate an ossified and universalizable theory of the human subject, nor because we wish to reduce human lives to states of discursive and linguistic subjectification. It is, rather, to recognize an important 'feature of human subjectivity: that we are born into and make ourselves under conditions that we may then choose to transform' (Moore 2011: 17). And a key aspect of this is how we manage relations to ourselves and to others - the human, the non-human and the inhuman (Moore 2011: 196) - how we act within, and attribute value to, the dynamic matrix of sociality.

The significance of this aspect of human subjectivity, and the need for a nuanced and multilayered theory of the ethical imagination, is evident from Nicholas Long's analysis of emergent forms of sociality in the online metaworld of Ultima Online. Inhabitants of Ultima Online regularly attest to their participation in, and enjoyment of, forms of communitarian sociality - but their claims are not supported by tracing the practices of social interaction that appear to generate their pleasure. Long argues that the affectively enabling sociality in Ultima Online would be better analysed in terms of Wilde's conception of sympathetic individualism rather than the commonality suggested by idioms of friendship or community, but that the resonance of these latter terms with users' established horizons of the good life makes those characterizations of the sociality an important element of its pleasure. His paper thus underscores that the ethical imagination can be both affective and perversely contradictory in ways linked to its political, intellectual and historical context - and suggests that relational 
matrices that finesse these contradictions might be those most powerfully experienced as 'utopian'.

Anne Allison's paper, by contrast, highlights what can happen when one loses the capacity to imagine the form of sociality one is used to, and is confronted head first with sociality's precarity. Tracing the unravelling of the sociality known as 'my-homeism' in post-war Japan, Allison shows how Japanese youth confronted with the 'hardship of life' have turned to violence, killing, and social withdrawal as the established horizons of their ethical imaginations are eroded and they struggle to find a new sense of purpose and completeness in the world. Allison's analysis reminds us of the fragility of wishedfor sociality, and its dependence on both the recognition of others and the macrological structures of political economy, such as the flexibilization of labour or the limited reach of state welfare. Yet her paper also traces emergent socialities that 'carry the potential of both futurity and hope' and, in doing this, she attests the enduring significance of the human ethical imagination, and its capacity to remake forms of sociality - for better or worse. While this remains true, a theory of human sociality cannot do without an understanding of the human subject. Or can it?

\section{Beyond Actor-Networks}

One of the most important contributions to recent anthropological theory has been Bruno Latour's ongoing reminder that humans live in a world replete with nonhuman entities, the agency of which allows them to serve as 'mediators through which inertia, durability, asymmetry, extension, domination is produced' (Latour 2007: 85). Given this, actor-network theorists propose that the notion of 'social' be redefined: phenomena should be considered 'social' if they are 'intrinsically interactive' or 'result from processes of assemblage or arrangement of entities, of whatever kind' (Cook et al. 2009: 55). This raises the question of whether 'sociality' would be better described in terms of a radical relationality, association, or assembly, and whether 'human sociality' is really a legitimate object of enquiry.

Some important insights are offered by Olga Solomon's paper, which draws on the interactions between autistic children in the U.S. and their therapy dogs to critically interrogate existing theories of human sociality. Arguing that these theories have placed too great an emphasis on the role of language, theory of mind, and the primacy of human-human interactions, she reveals how interactions with therapy dogs might allow children diagnosed as autistic to recognize their own capacities to enjoy sustained and fulfilling relations with others: the dogs themselves, but also humans they go on to encounter at home and at school. Solomon employs the concept of 'worlding' to analyse this encounter, foregrounding how diverse entities co-shape each other in ongoing, and open-ended, processes of becoming to co-constitute 'figured worlds', thereby changing their grasps of the dynamic matrices in which they are emplaced.

While it would therefore not be inaccurate to describe the coming together of child and dog (and therapists, parents, etc.) in terms of an assemblage or association, nor to theorize the dog as a non-human actant, to equate this with a generic sociality - of the kind that could be found in any instance of relations in an assemblage - strikes us as impoverished. It tells us nothing about those factors that allow the encounter to have 
the consequences that it does: the dog's disposition - a result of intensive training of the specific therapy dog, as well as millennia of selective breeding within its species; and the child's capacities to imagine a way of being other than that which it has experienced previously, to act upon that visualization, and to remember and project that encounter into future encounters with others - something that remains significant long after the assemblage has been dismantled. To understand these requires a theory of (autistic) human sociality, and a theory of (therapy) dog sociality.

Although actor-network approaches have often been caricatured as hostile to the study of humans (McLean and Hassard 2004), they actually offer a perfect lead into a revitalized study of human sociality. Insisting that humans are embedded in a world of multifarious actants, they nevertheless recognize that diverse actants have their own incommensurable agencies which should be taken on their own terms (Latour 2007: 74). This, of course, includes humans themselves. So when Latour (2010: 81) suggests it is time for ANT to move on to be a 'fully colourized' rendering of associations, paying close attention to the world's many different modes of connection and modes of existence, we would concur, arguing that a theory of human sociality of the kind we have outlined in this introduction will be essential for any such enterprise.

\section{Beyond Affect}

Latour's interest in the material semiotics of assemblages is also shared by a growing body of work, sometimes styling itself as 'affect theory', which emphasizes that the (human) body is itself an assemblage of materials - cells, nerves, fluids - that are constantly in a state of becoming, and that the social sciences should attend to ways in which bodies are engaged with in their biological specificity, beneath or before the level at which cognitive processes relating to language, representation, or consciousness might occur (Connolly 2002; Massumi 2002; Thrift 2006; Clough 2008).This has led to some writers raising the possibility that collective phenomena, like the swarming or flocking of birds, might be driven by affective processes (Venn 2010), and even the proposition that 'sociality is a matter of affective transmissions across bodies in a machinic assemblage with technology and technical arrangements' (Clough 2010: 225).

Jo Vergunst and Anna Vermehren's analysis of a 'social art' project in the Scottish town of Huntly demonstrates the limitations of such an approach. This art project sought to 'slow down' Huntly, challenging participants to participate in events such as coordinated cycling through the town at a very slow speed. Vergunst and Vermehren note that this raises important questions about the cadence, rhythm, and pace of sociality, since moving slowly together fostered an atmosphere of 'sociability' that stood in sharp contrast with more typical British socialities of cycling.

Here theories of affect could provide a potential interpretive lens, just as Venn (2010) has suggested it is affective energies that keep flocks of birds, and assemblages of humans, in formation. But Vergunst and Vermehren's ethnography points to different conclusions. Moving together slowly had to be learned, and required both political negotiation with local businesses and on-the-day reiteration by the artist. People participated in the artwork because they were intrigued by the prospect of experiencing novel affectivities. Finally, the artwork's mundane setting - participants' home town - 
meant their bodily experiences opened up new possibilities for the town and its sociality might be changed for the better in years to come. Here, sociality - its affectivity included - was both generated by and generative of participants' ethical imaginations. Moreover, as Vergunst and Vermehren argue by drawing on Schutz's notion of consociation, these outcomes were underpinned by the capacity of shared (bodily) experience to foster shared understanding, meaning, and intersubjective knowledge. While attention to affective experience enriches our understanding of human sociality, it would be quite wrong to suggest that affect is 'pre-social' or generic; its role has to be understood in relation to the distinctive imaginative, ethical, and representative capacities of human subjects (see also Moore, this collection).

\section{Conclusion}

The importance of imagination and anticipation in all of the papers in this collection underscores that there is a crucial element of human sociality that is very poorly captured by theories that emphasize material co-presence alone. This is what Moore (this collection) terms the 'human capacity for virtuality, for endowing things of the imagination and the mind with meaning and significance. Indeed, as we have seen, this capacity is always being deployed, via practices of ethical imagination, in human sociality. This is why it is so problematic to offer any bounded 'definition' of what comprises human sociality; and also why it is always being taken in new directions. This is also why the notion of dynamic relationality will not suffice as an anthropological theory of sociality; it needs to be combined with an attention to those aspects of existence within a relational matrix that are distinctively human.

\section{References}

Bersani, L. 2000. Sociality and Sexuality. Critical Inquiry 26, no. 4: 641-656.

Chau, A. Y. 2006. Miraculous Response: Doing Popular Religion in Contemporary China. Stanford: Stanford University Press.

Clough, P. T. 2008. The Affective Turn: Political Economy, Biomedia and Bodies. Theory Culture and Society 25, no. 1: 1-22.

2010. Afterword: The Future of Affect Studies. Body and Society 16, no. 1: 222-230.

Connolly, W. 2002. Neuropolitics. Minneapolis: University of Minnesota Press.

Cook, J., J. Laidlaw and J. Mair. 2009. What If There Is No Elephant? Towards a Conception of an Un-Sited Field. In Multi-Sited Ethnography: Theory, Praxis and Locality in Contemporary Social Research (ed.) M.-A. Falzon, 47-72. Aldershot: Ashgate.

Foucault, M. 1997. Friendship as a Way of Life. In Essential Works of Michel Foucault, Vol. 1: Ethics: Subjectivity and Truth (ed.) P. Rabinow, 135-140. New York: The New Press.

Haver, W. 1996. The Body of This Death: Historicity and Sociality in the Time of Aids. Stanford: Stanford University Press.

Latour, B. 2007. Reassembling the Social: An Introduction to Actor-Network-Theory. Oxford: Oxford University Press.

2010. A Plea for Earthly Sciences. In New Social Connections: Sociology's Subjects and Objects (eds.) J. Burnett, S. Jeffers and G. Thomas, 72-84. New York: Palgrave Macmillan.

Massumi, B. 2002. Parables for the Virtual: Movement, Affect and Sensation. Durham: Duke University Press. 
McLean, C. and J. Hassard. 2004. Symmetrical Absence/Symmetrical Absurdity: Critical Notes on the Production of Actor-Network Accounts. Journal of Management Studies 41, no. 3 : 493-519.

Moore, H. L. 2011. Still Life: Hopes, Desires and Satisfactions. Cambridge: Polity Press.

Strathern, M., J. Peel, C. Toren, J. Spencer and T. Ingold. 1990. The Concept of Society Is Theoretically Obsolete. Manchester: GDAT.

Sunder Rajan, K. 2008. Biocapital as an Emergent Form of Life: Speculations on the Figure of the Experimental Subject. In Biosocialities, Genetics and the Social Sciences (eds.) S. Gibbon and C. Novas, 157-187. London: Routledge.

Thrift, N. 2006. Space, Place and Time. In The Oxford Handbook of Contextual Political Analysis (eds.) R. E. Goodin and C. Tilly, 547-563. Oxford: Oxford University Press.

Tuhkanen, M. 2005. Foucault's Queer Virtualities. rhizomes 11.<http://www.rhizomes.net/ issue11/tuhkanen.html> (accessed 30 September 2011.)

Venn, C. 2010. Individuation, Relationality, Affect: Rethinking the Human in Relation to the Living. Body and Society 16, no. 1: 129-161.

Nicholas J. Long is a British Academy Postdoctoral Fellow in Social Anthropology at the University of Cambridge, a Junior Research Fellow at St Catharine's College, Cambridge, and author of Being Malay in Indonesia (NUS/KITLV/University of Hawai' $\mathrm{i}$ Press, forthcoming).

Henrietta L. Moore is the William Wyse Chair of Social Anthropology at the University of Cambridge. Her most recent book is Still Life: Hopes, Desires and Satisfactions (Cambridge: Polity, 2011). 